sensitivity, specificity and positive and negative predictive values (PPV, NPV) were evaluated to determine the diagnostic accuracy of the two methods.

Results: Most of the patients were receiving GC treatment for vasculitis or polymyalgia rheumatica over a mean period of $47.7 \pm 69$ months at a mean daily dose of $14.5 \mathrm{mg} .17 \%$ had VF, $28 \%$ any type of fragility fracture (VF + no-VF), 29\% OP and 71\% DMA. In patients with VF, low TBS (DMA) was more common than densitometric OP $(76 \%, p=0.03$ vs. $38 \%, p=n . s)$. Similar results were observed when analysing patients with any fragility fracture $(69 \%, p=0.02$ vs. $36 \%, p=n . s)$. The diagnostic accuracy of TBS was greater than BMD on evaluating VF, with a sensitivity, specificity, PPV and NPV of $0.76,0.53,0.25$ and 0.92 for TBS and $0.38,0.72,0.22$, and 0.85 for BMD, respectively. Specificity increased to 0.89 for VF and 0.9 for any fragility fracture on combining both assessments (OP+DMA).

Conclusion: TBS has greater discriminative power than BMD measurement and could be useful as a complementary tool for fracture risk assessment in GIOP.

Disclosure of Interests: Helena Florez: None declared, José HernándezRodríguez : None declared, Africa Muxi: None declared, Josep Lluís Carrasco: None declared, Sergio Prieto-González: None declared, Silvia RuizGaspà : None declared, Maria C. Cid Grant/research support from: Kiniksa Pharmaceuticals, Consultant for: Roche, GSK, Janssen, Abbvie, Speakers bureau: Boehringer-Inhelheim, Vifor, Ana Monegal Speakers bureau: Eli Lilly, Amgen, Núria Guañabens Consultant for: Advisory Boards from Amgen, Alexion and UCB, Speakers bureau: Fees and lectures from Eli Lilly, Pilar Peris Speakers bureau: Personal Fees and Non-financial support (attendance to congresses) from Amgen and Eli Lilly

DOI: 10.1136/annrheumdis-2019-eular.2287

\section{FRI0488 ROLE OF DUAL-PHOTON X-RAY ABSORPTIOMETRY (DXA) IN PREDICTION OF REFRACTURE AND MORTALITY}

Sara Ganhão ${ }^{1}$, Miguel Guerra ${ }^{2}$, Francisca Aguiar ${ }^{1}$, Raquel Ferreira ${ }^{1}$, Teresa Martins-Rocha ${ }^{1}$, Ana Filipa Águeda ${ }^{3}$, Georgina Terroso ${ }^{1}$, Eva Mariz ${ }^{1}$ Carlos Vaz ${ }^{1,4}$, Lúcia Costa ${ }^{1} .{ }^{1}$ Centro Hospitalar e Universitário de São João, Department of Rheumatology, Oporto, Portugal; ${ }^{2}$ Centro Hospitalar de Vila Nova de Gaia/Espinho, Department of Rheumatology, Vila Nova de Gaia, Portugal; ${ }^{3}$ Centro Hospitalar do Baixo Vouga, Department of Rheumatology, Aveiro, Portugal; ${ }^{4}$ Faculty of Medicine of Oporto University, Oporto, Portugal

Background: The presence of a fragility fracture leads to a high risk for a subsequent fracture and mortality. Although bone mineral density (BMD) does not reflect the real fracture risk in many conditions, it is a wellestablished predictor of fracture risk and for many years, dual-photon Xray absorptiometry (DXA) has been the reference standard for measuring BMD.

Objectives: To evaluate the predictive significance of femur BMD and Tscore obtained by DXA in the outcomes refracture and mortality of elderly patients with a previous fragility hip fracture.

Methods: Longitudinal retrospective study of patients referred to the Rheumatology department's Fracture Liaison Service (FLS) from march 2015 until march 2017 aged $\geq 65$ years old. Demographic and clinical data were collected including DXA results. Statistical analysis was performed with STATA. Hazard ratios (HR) were calculated through cox regression, adjusted to age and degree of dependence.

Results: From a total of 522 patients, 214 performed DXA (77.6\% female; median (min-max) age 82 (65-99) years; $65.4 \%$ autonomous). Twenty seven patients died (median days until death=457, min 160, max 1049) and 18 had a subsequent fracture (median days until refracture 343.5, $\min 160, \max 1049) ; 129$ patients maintained follow-up. Mean serum total femur BMD, $\mathrm{g} / \mathrm{cm}^{2}$ (SD) was 0.7 (0.14) and mean total femur T-score (SD) was -2.6, (1.1). 127 (59.3\%) patients had T-score $\leq-2.5$. After multivariable analysis, higher femur BMD and T-score were predictors of better survival outcome (HR 0.01, $p=0.023$; HR 0.67, $p=0.038$, respectively). Nevertheless, none of them predicted refracture outcome. (HR: 0.08; $95 \% \mathrm{Cl} \quad[0.01-5.16] ; p=0.240) ; \mathrm{HR}: 0.81 ; 95 \% \mathrm{Cl}[0.51-1.28]$; $p=0.361$ ).

Conclusion: DXA is important in the management of patients with bone fragility syndromes. Our sample suggests that femur BMD/T-score had significant impact on survival outcome. Thus it can be a predictor of mortality with relevant role in daily practice.

\section{REFERENCES:}

[1] Browner WS, Seeley DG, Vogt TM, Cummings SR. Non-trauma mortality in elderly women with low bone mineral density. Study of Osteoporotic Fractures Research Group. Lancet 1991;338:355-8.

[2] Trivedi DP, Khaw KT. Bone mineral density at the hip predicts mortality in elderly men. Osteoporos Int 2001;12:259-65.

[3] Cortet B. Does low bone mineral density predict mortality? Joint Bone Spine. 2016 Dec;83(6):623-624

[4] Roux $\mathrm{C}^{1}$, Briot $\mathrm{K}^{2}$. Current role for bone absorptiometry. Joint Bone Spine. 2017 Jan;84(1):35-37.

[5] Cummings SR, Black DM, Nevitt MC, Browner W, Cauley J, Ensrud K,et al. Bone density at various sites for prediction of hip fractures. The Study of Osteoporotic Fractures Research Group. Lancet. 1993:341:72-75.

Disclosure of Interests: None declared

DOI: 10.1136/annrheumdis-2019-eular.5066

\section{FRI0489 THE ASSOCIATION BETWEEN CT-MEASURED BONE ATTENUATION AND PREVALENT VERTEBRAL FRACTURES IN THE THORACIC SPINE DIFFERS ACCORDING TO VERTEBRAL FRACTURE LOCATIONS}

Mayke J van Dort ${ }^{1}$, Annemariek Driessen ${ }^{2}$, Joop van den Bergh ${ }^{1}$, Emiel

Fm Wouters ${ }^{1}$, Elisabeth AM Romme ${ }^{3}$, Frank Wjm Smeenk ${ }^{3}$, Bert van Rietbergen ${ }^{4}$ Piet Geusens ${ }^{1} .{ }^{1}$ Maastricht University, Maastricht, Netherlands; ${ }^{2}$ Maastrcht

University, Maastyricht, Netherlands; ${ }^{3}$ Catharina Hospital, Eindhoven, Netherlands; ${ }^{4}$ TU Eindhoven, Eindhoven, Netherlands

Background: Subjects with prevalent vertebral fractures (VFs) have lower bone mineral density (BMD) in the lumbar spine and hip than subjects without prevalent VFs. However, VFs are not equally distributed across the thoracic spine. They occur preferentially at T7-T8 and T11-T12, which are the highest loaded vertebral regions during daily activities (1).

Objectives: We evaluated the association of BMD with prevalent VFs at non-preferential locations (nprVFs: T4-T6 and T9-T10) and at preferential locations (prVFs: T7-T8 and T11-T12).

Methods: Baseline CT images of T4-T12 in smokers with and without COPD were analysed for the presence of VFs according to Genant Bone attenuation (BA), expressed in Hounsfield units (HU), was measured in all non-fractured vertebrae. Linear regression was used to compare mean BA and logistic regression was used to estimate the association between BA and prevalent VFs. All analyses were adjusted for age and sex.

Results: Prevalent VFs were most frequently located at T7-T8 (in $>6 \%$ of vertebrae) and $\mathrm{T} 11-\mathrm{T} 12$ (in $>4 \%$ of vertebrae).

At subject level and compared to subjects without prevalent VFs, mean BA of all non-fractured vertebrae was significantly lower in subjects with any prevalent VFs $(-21 \%, p<0.0001)$. There was a significant progressive trend $(p<0.0001)$ in decrease in mean BA of all non-fractured vertebrae between subjects with only prVFs $(-15 \%)$, with only nprVFs $(-25 \%$, $p<0.05$ vs prVFs) and with both nprVFs and prVFs combined $(-32 \%$, $p<0.0001$ vs prVFs) (all $p<0.0001$ compared to subjects without VF). At each individual non-fractured vertebral level, each BA decrease of 50 $\mathrm{HU}$ was associated with a 2.0-2.5 increased odds of any prevalent VF, a 1.5-1.9 increased odds of only prVF, a 2.2-3.4 increased odds of only nprVF and a 3.8-4.6 increased odds of nprVF and prVF combined.

Conclusion: In addition to BA, other factors such as vertebral load during daily activities may determine the location of a VF. The location of a VF may be a potential in vivo marker of the load/strength ratio of bone.

\section{REFERENCES:}

[1] Bruno AG, Burkhart K, Allaire B, Anderson DE, Bouxsein ML. Spinal Loading Patterns From Biomechanical Modeling Explain the High Incidence of Vertebral Fractures in the Thoracolumbar Region. J Bone Miner Res. 2017 Jun;32(6):1282-1290

Disclosure of Interests: Mayke J van Dort: None declared, Annemariek Driessen: None declared, Joop van den bergh Grant/research support from: Grants/research support from Eli Lily, Sanofi, Amgen., Emiel FM Wouters: None declared, Elisabeth AM Romme: None declared, Frank WJM Smeenk: None declared, Bert van Rietbergen: None declared, Piet Geusens Grant/research support from: Research support, consultant and/ or speaker fees from: Pfizer, Abbott, Eli Lilly, Amgen, MSD, Roche, UCB, BMS, Novartis, Will-Pharma, Grant/research support from: Pfizer, 